\title{
Recurrent Aphthous Stomatitis in Children: A Practical Guideline for Paediatric Practitioners
}

\author{
Romana Koberováa,*, Vlasta Merglová2, Vladimíra Radochová ${ }^{1}$
}

\begin{abstract}
Recurrent aphthous stomatitis (RAS) is the most common chronic oral mucosal lesion affecting up to $25 \%$ of the population. The diagnosis is based on well-defined clinical characteristics, but the precise aetiology and pathogenesis remain unclear. The treatment of RAS should be based on the identification and control of possible predisposing factors. A wide range of topical medicaments is available as antiseptics, anti-inflammatory drugs and corticosteroids. The systemic treatment is indicated in patients with continuous and aggressive manifestation, which is extremely rare in children. The present article provides a review of the current concept and knowledge of the aetiology, pathogenesis, and management of RAS in the paediatric population.
\end{abstract}

\section{KEYWORDS}

recurrent aphthous stomatitis; children; pathogenesis; treatment

AUTHOR AFFILIATIONS

${ }^{1}$ Department of Dentistry, Faculty of Medicine in Hradec Králové, Charles University, and University Hospital in Hradec Králové, Czech Republic

2 Department of Dentistry, Faculty of Medicine, Charles University and University Hospital in Pilsen, Czech Republic

* Corresponding author: Department of Dentistry, Sokolská 581, 50005 Hradec Králové, Czech Republic; e-mail: KoberovaR@lfhk.cuni.cz

Received: 5 June 2020

Accepted: 30 July 2020

Published online: 22 December 2020

Acta Medica (Hradec Králové) 2020; 63(4): 145-149

https://doi.org/10.14712/18059694.2020.56

(c) 2020 The Authors. This is an open-access article distributed under the terms of the Creative Commons Attribution License (http://creativecommons.org/licenses/by/4.0), which permits unrestricted use, distribution, and reproduction in any medium, provided the original author and source are credited. 


\section{INTRODUCTION}

Aphthae (cancer sores) is one of the most commonly recorded painful lesions in the oral cavity and were first mentioned by Hippocrates (460-370 BC) who utilized the term "aphthai" (1). Recurrent aphthous stomatitis (RAS) is characterized by multiple recurrent small, round, or ovoid ulcers with circumscribed margins, erythematous haloes, and yellow or grey floors. They typically present in children and adolescents (2). Up to $25 \%$ of the population can be affected by aphthae. It is a disease with high recurrence rate (50\% at 3 months). Aphthae are more common in females (3). Many predisposing factors have been identified. These include especially local trauma, genetic factors, nutritional deficiencies, viral and bacterial infections or immune and endocrine disease (4). All forms of aphthous ulcers have a significant impact on the quality of life and interfere with the child's well-being.

\section{PATHOGENESIS}

Several theories have described the pathogenesis of RAS. Significant interactions between the immune system, genetics and environmental factors play a significant role. DNA damage secondary to oxidative stress is thought to play a role in RAS (5). Evidence suggests an immunological basis for chronic inflammation. T cell-mediated immunity plays a significant role in RAS development. The imbalance between CD4+ and CD8+ T lymphocytes (decreased ratio) is very frequent observation. In patients with RAS. $T$ cells are responsible for epithelial destruction via generated TNF- $\alpha$. TNF- $\alpha$ has been found to be significantly increased in the saliva of RAS patients. A recent study explored the significance of single nucleoid polymorphisms in the genes for pro-inflammatory cytokines IL-1 and IL-6. This suggests a genetic component to the immuno-pathogenesis of RAS (6). The results of the recent case-control study strongly indicated that RAS patients have a systemic imbalance in the oxidant-to antioxidant ratio favouring oxidative damage (7). It is currently thought that an

Tab. 1 Systemic disorders associated with RAS (25).

\begin{tabular}{|l|}
\hline Behcet's syndrome \\
\hline Celiac disease \\
\hline Cyclic neutropenia \\
\hline Nutritional deficiencies (iron, folate, zinc, B1, B2, B6, B12) \\
\hline IgA deficiency \\
\hline Immunocompromised conditions, including HIV disease \\
\hline Inflammatory bowel disease \\
\hline $\begin{array}{l}\text { MAGIC syndrome (mouth and genital ulcers with inflamed carti- } \\
\text { lage) }\end{array}$ \\
\hline $\begin{array}{l}\text { PFAPA syndrome (periodic fever, aphthous stomatitis, } \\
\text { pharyngitis, cervical adenitis) }\end{array}$ \\
\hline Reactive arthritis \\
\hline Sweet's syndrome \\
\hline Ulcus vulvae acutum \\
\hline
\end{tabular}

unknown antigen stimulates keratinocytes, resulting in cytokine secretion and leukocyte chemotaxis. The RAS may also be associated with a specific HLA haplotype such as HLA-A2, A11, B12 and DR2 (8).

\section{PREDISPOSING AND ENVIRONMENTAL FACTORS}

\section{LOCAL FACTORS}

Local trauma during mastication or tooth brushing is regarded as a possible cause of RAS $(2,9)$. Trauma predisposes to RAS by inducing oedema, early cellular inflammation associated with increased viscosity of the oral submucosal extracellular matrix (10). Some changes in salivary composition, such as $\mathrm{pH}$, and stress-induced salivary cortisol have been correlated with RAS (11).

\section{DRUGS}

Boulinguez et al. reported the association between some drugs as non-steroid anti-inflammatory drugs (NSAID) or b-blockers and RAS (12).

\section{FOOD HYPERSENSITIVITY}

Some foods such as chocolate, coffee, peanuts, cereals, almonds, strawberries, tomatoes, and wheat flour (containing gluten) are considered as predisposing factors (13). Besu et al. published the study reporting the strong association between high levels of serum anti cow's milk proteins and clinical manifestations of RAS (14).

\section{NUTRITIONAL DEFICIENCY}

Nutritional deficiencies associated with anaemia (iron, serum ferritin) have been reported to be common in RAS paediatric patients (15). Deficiencies of vitamin B1, B2, and/or B6 are also common (16).

\section{HEREDITARY PREDISPOSITION}

At least $40 \%$ of RAS patients have a familiar history of RAS (17). Children with RAS positive parents have a $90 \%$ chance of developing RAS. When patients have a positive family history, they tend to develop recurrent aphthous ulcers at an early age. They aphthous lesions appear more frequently and demonstrate severe symptoms. Studies of identical twins have also shown the hereditary nature of this disorder $(18,19)$.

\section{THE SYSTEMIC DISORDERS}

Several systemic disorders have been reported to be associated with RAS. The clinical and morphological findings are not distinguishable from those found in healthy individuals. The systemic disorders that are associated with lesions clinically similar to RAS are shown in Table 1 . The celiac disease represents one of the frequent associations in children (20). Mucosal aphthosis is a feature of a systemic syndrome that includes recurrent fever with unknown source of infection (21). Such syndromes are referred to 
Tab. 2 Clinical features of minor, major and herpetiform recurrent aphthous stomatitis (RAS) (36).

\begin{tabular}{|c|c|c|c|}
\hline & Minor RAS & Major RAS & Herpetiform RAS \\
\hline Gender predilection & Equal & Equal & Girls \\
\hline Morphology & $\begin{array}{l}\text { Round or oval lesions, covered } \\
\text { by grey-white pseudomembranes, } \\
\text { erythematous halo }\end{array}$ & $\begin{array}{l}\text { Round or oval lesions, covered } \\
\text { by grey-white pseudomembranes, } \\
\text { erythematous halo }\end{array}$ & $\begin{array}{l}\text { Small, deep ulcers. } \\
\text { Irregular contour }\end{array}$ \\
\hline Distribution & Lips, cheeks, tongue, mouth floor & Lips, soft palate, pharynx & $\begin{array}{l}\text { Lips, cheeks, tongue, mouth floor, } \\
\text { gingiva }\end{array}$ \\
\hline Number of ulcers & $1-5$ & $1-10$ & $10-100$ \\
\hline Size of ulcers & $<10 \mathrm{~mm}$ & $<10 \mathrm{~mm}$ & $2-3 \mathrm{~mm}$ \\
\hline Prognosis & $\begin{array}{l}\text { Lesions resolve in } 4-14 \text { days, } \\
\text { no scaring }\end{array}$ & $\begin{array}{l}\text { Lesions persist }>6 \text { weeks, } \\
\text { high risk of scaring }\end{array}$ & $\begin{array}{l}\text { Lesions resolve in }<30 \text { days, } \\
\text { scarring uncommon }\end{array}$ \\
\hline
\end{tabular}

as auto-inflammatory diseases as PFAPA (periodic fever, aphthous stomatitis, pharyngitis, cervical adenitis) (22). The RAS can also be part of various neutrophilic dermatoses (23). The stress remains one of the significant factors affecting the immune system and is believed to predispose patients to RAS (24).

\section{CLINICAL FEATURES}

There are three clinical representations of RAS: minor ( $<70 \%$ of cases), major ( $10 \%)$, and herpetiform ulceration (10\%) (Table 2). Recurrent aphthous stomatitis comprises recurrent bouts of one or more rounded, shallow, painful ulcers at intervals of a few months to a few days. Patients may have prodromal symptoms of tingling or burning before the appearance of the lesions. During this initial period, a localized area of erythema develops. Within hours, a small white papule forms, ulcerates, and gradually enlarges over the next 48-72 hours (26).

\section{MINOR RAS}

Minor RAS (also known as Mikulicz's aphthae) is the most prevalent form and typically occurs in children who are 5 to 18 years old (27). They affect only non-keratinized parts of mucosa. Superficial, round ulcerations are $<10 \mathrm{~mm}$, accompanied by a grey pseudomembrane and erythematous halo (Figure 1). They usually occur on non-keratinized mucosa of the labial and buccal mucosa, the floor of the mouth and ventral or lateral surface of the tongue. The ulcers heal within 10-14 days without scarring.

\section{MAJOR RAS}

Major RAS (or Sutton's disease or periadenitis mucosa necrotica recurrens) is less common; they are larger than 10 $\mathrm{mm}$ in diameter, more profound, often scared (Figure 2). These lesions have a predilection for lips, soft palate and tonsils. Lesions may appear on any mucosal surface. These lesions take up to 6 weeks to heal. The onset is usually after puberty and recurrence can last for decades.

\section{HERPETIFORM ULCERATION}

Herpetiform ulcerations (or Cooke's) constitute only $5-10 \%$ and are very rare in children (28). These lesions are small and multiple, typically affected lateral margins and ventral surface of the tongue and floor of the mouth. Individual ulcers are grey with an irregular contour. A single crop of ulcers may last for 7-14 days, making eating and speaking difficult (26).

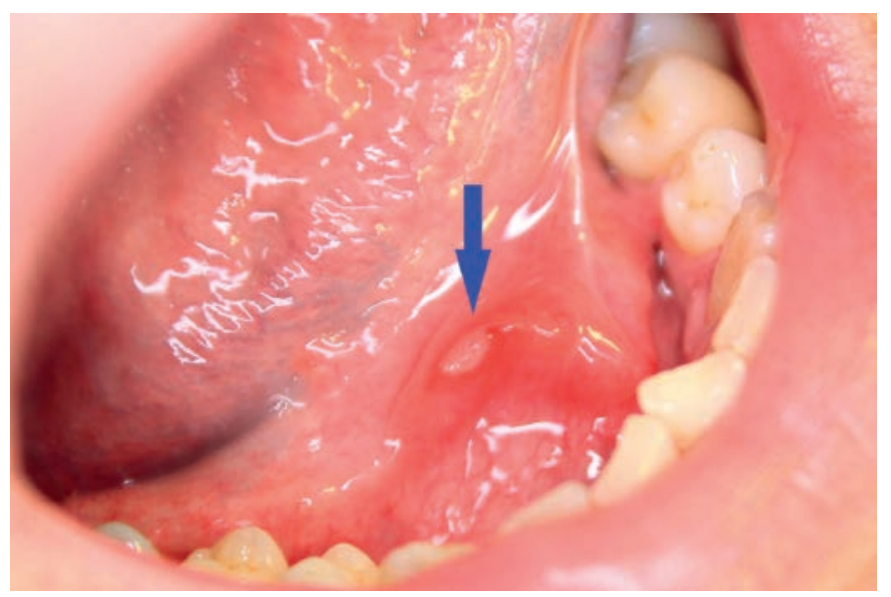

Fig. 1 Aphtha minor.

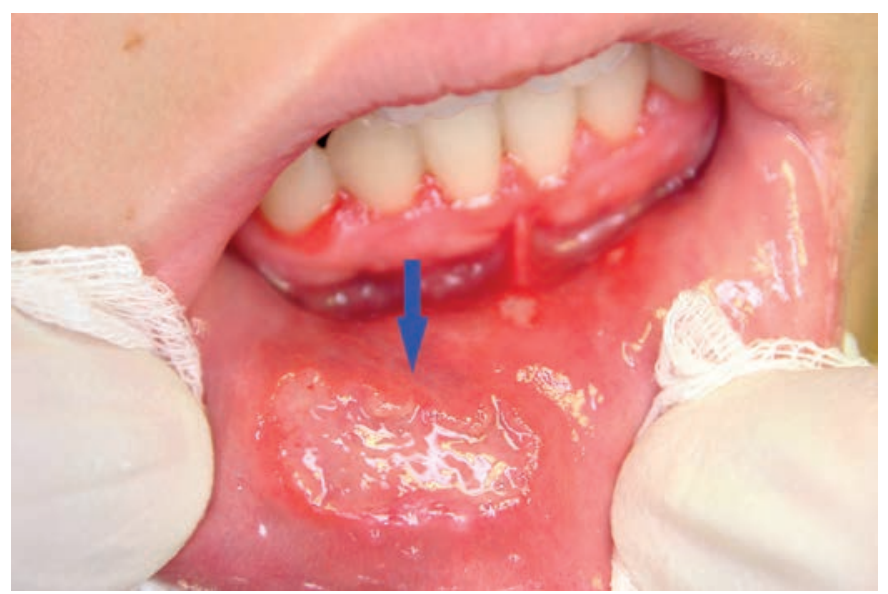

Fig. 2 Aphtha major. 


\section{DIAGNOSIS}

No specific diagnostic test exists to diagnose RAS. The correct diagnosis of RAS is dependent on a detailed clinical history and examination of the ulcers. Usually, it does not cause difficulties because of the clinical appearance and recurrence of the lesions. It is necessary to point out the possible problems in the differential diagnosis when aphthous stomatitis is considered as changes typical for herpetic gingivostomatitis with systemic prodromal symptoms that are absent in RAS. Histological examination is characteristic but not specific for RAS. Central ulceration covered by fibro purulent membrane is a frequent finding in early stages (29). Mixed inflammatory infiltrate is present in adjacent connective tissues. The histopathological examination is sometimes necessary to differentiate aphthous ulcers from other mucocutaneous diseases that have ulcerative manifestations such as neoplastic lesions. To rule out potential viral causes such as varicella zoster virus infections, herpangina, hand-foot-and-mouth disease or Coxsackie virus-related oral ulcers it is sometimes necessary to do microbiological examination (either direct or indirect diagnostics). Underlying systemic conditions should be identified (celiac disease, IBD, hematologic disorders, nutritional deficiencies) (30).

\section{TREATMENT}

The current concept of the management of RAS is aimed at supportive care. It is necessary to point out that once the development of lesion starts, it is not possible to stop the pathogenetic process. No pharmacological treatment has been curative, although several modalities have been effective in decreasing pain and erythema and increasing the rate of re-epithelialization of the lesions. The comfort of the treatment procedures (application form, frequency, and discomfort in the oral cavity) should be taken into consideration, particularly in paediatric patients. The positive fact is that children suffer most from minor lesions, but the treatment modalities are limited by the age and cooperation of the child. It is reasonable to begin treatment with topical medication. Topical treatment is aimed at prevention of superinfection, protection of existing ulcers, analgesia, decreasing inflammation, and treating active ulcers. Systemic therapy is exceptional in children. The systemic treatment is considered only in children with immunity defects (26).

\section{TOPICAL AGENTS}

Local anaesthetics (lidocaine, benzocaine, polidocanol) have a benefit in pain relieve. It is particularly important in children when painful lesions may lead to eating difficulties and dehydration. Possible application forms are solutions, gels, and adhesive pastes. A notable fact is a cooperation of the child; therefore, adhesive pastes are preferred in small children.

Antiseptics (chlorhexidine gluconate, benzydamine hydrochloride, triclosan, cetylpyrimidiumchlorid) prevent the secondary infection and may relieve symptoms. The different application forms are available.
Based on the immunologic nature of RAS, topical steroids may often control RAS. Topical triamcinolone or stronger steroids such as betamethasone may be used. Steroids act on the lymphocytes and alter the response of effector cells to precipitants of immunopathogenesis (31).

\section{SYSTEMIC MEDICATIONS}

Systemic treatment is indicated for severe and recurring ulcerations where topical management is not sufficient. Options for systemic treatment include the use of immunomodulatory drugs such as corticosteroids, dapsone, colchicine, tetracycline, thalidomide or biologic agents (such as TNF- $\alpha$ inhibitors). The use of these compounds is significantly limited in children, whereas the use of most of them except steroids is usually contraindicated. Treatment with systemic steroids provides an only transient response of RAS (32). Long term steroid use in RAS is not indicated.

Treatment with vitamin B12 has been suggested. Duration of ulcers and pain has been reduced in the study by Volkov showing a benefit of vitamin B12 administration (33).

One of the possible drugs is pentoxifylline inhibiting TNF- $\alpha$ production and other pro-inflammatory cytokines (34). This drug is, however, not indicated in children up to 18 years of age. Most of other medications for the systemic application have a significant immunosuppressive effect, and their indication is hardly justifiable in childre (35).

\section{OTHER THERAPEUTIC}

AND PROPHYLACTIC MEASURES

The parents and the child should be informed to minimize the local traumatization of the oral mucosa, modify the diet, eliminate possible allergic agents, and reduce the emergence of stressful situations. Proper oral hygiene in older children is essential.

\section{CONCLUSION}

RAS remains a common oral mucosal disorder in the paediatric population. Its aetiology remains unclear. No specific trigger has ever been demonstrated. There is no safe therapy to ensure no recurrence of RAS. In severe cases, the complex paediatric examination of the child is recommended to eliminate the similarly looking oral manifestation of systemic diseases as anaemias, idiopathic gastrointestinal disturbances (celiac disease) and hypersensitivity to various allergens.

\section{ACKNOWLEDGEMENTS}

The work was supported by the project PROGRES Q29 (Charles University) and by the Czech Health Research Council, Ministry of Health of the Czech Republic and $\mathrm{MH}$ CZ - DRO (UHHK, 00179906). 


\section{CONFLICTS OF INTEREST}

\section{None declared.}

\section{REFERENCES}

1. Rennie JS, Reade PC, Hay KD, Scully C. Recurrent aphthous stomatitis. Br Dent J 1985; 159: 361-7.

2. Jurge S, Kuffer R, Scully C, Porter SR. Mucosal disease series. Number VI. Recurrent aphthous stomatitis. Oral Dis 2006; 12: 1-21.

3. Barrons RW. Treatment strategies for recurrent oral aphthous ulcers. Am J Health-Syst Pharm 2001; 58: 41-50.

4. Belenguer-Guallar I, Jiménez-Soriano Y, Claramunt-Lozano A. Treatment of recurrent aphthous stomatitis. A literature review. J Clin Exp Dent 2014; 6: e168-e174.

5. Edgar NR, Saleh D, Miller RA. Recurrent Aphthous Stomatitis: A Review. J Clin Aesthetic Dermatol 2017; 10: 26-36.

6. Najafi S, Yousefi H, Mohammadzadeh M, et al. Association study of interleukin-1 family and interleukin- 6 gene single nucleotide polymorphisms in recurrent aphthous stomatitis. Int J Immunogenet 2015; 42: 428-31.

7. Tugrul S, Koçyiğit A, Doğan R, et al. Total antioxidant status and oxidative stress in recurrent aphthous stomatitis. Int J Dermatol 2016 55: e130-e135.

8. Albanidou-Farmaki E, Deligiannidis A, Markopoulos AK, Katsares V, Farmakis K, Parapanissiou E. HLA haplotypes in recurrent aphthous stomatitis: a mode of inheritance? Int J Immunogenet 2008; 35: 427-32.

9. Wray D, Graykowski EA, Notkins AL. Role of mucosal injury in initiating recurrent aphthous stomatitis. Br Med J Clin Res Ed 1981; 283 1569-70.

10. Stone OJ. Aphthous stomatitis (canker sores): a consequence of high oral submucosal viscosity (the role of extracellular matrix and the possible role of lectins). Med Hypotheses 1991; 36: 341-4.

11. McCartan BE, Lamey PJ, Wallace AM. Salivary cortisol and anxiety in recurrent aphthous stomatitis. J Oral Pathol Med 1996; 25: 357-9.

12. Boulinguez S, Cornée-Leplat I, Bouyssou-Gauthier ML, Bedane C, Bonnetblanc JM. [Analysis of the literature about drug-induced aphthous ulcers]. Ann Dermatol Venereol 2000; 127: 155-8.

13. Hay KD, Reade PC. The use of an elimination diet in the treatment of recurrent aphthous ulceration of the oral cavity. Oral Surg Oral Med Oral Pathol 1984; 57: 504-7.

14. Besu I, Jankovic L, Magdu IU, Konic-Ristic A, Raskovic S, Juranic Z. Humoral immunity to cow's milk proteins and gliadin within the etiology of recurrent aphthous ulcers? Oral Dis 2009; 15: 560-4.

15. Porter SR, Scully C, Flint S. Hematologic status in recurrent aphthous stomatitis compared with other oral disease. Oral Surg Oral Med Oral Pathol 1988; 66: 41-4.

16. Nolan A, McIntosh WB, Allam BF, Lamey PJ. Recurrent aphthous ulceration: vitamin B1, B2 and B6 status and response to replacement therapy. J Oral Pathol Med 1991; 20: 389-91.

17. Natah SS, Konttinen YT, Enattah NS, Ashammakhi N, Sharkey KA, Häyrinen-Immonen R. Recurrent aphthous ulcers today: a review of the growing knowledge. Int J Oral Maxillofac Surg 2004; 33: 221-34.

18. Ship II. Epidemiologic aspects of recurrent aphthous ulcerations. Oral Surg Oral Med Oral Pathol 1972; 33: 400-6.

19. Miller MF, Garfunkel AA, Ram C, Ship II. Inheritance patterns in recurrent aphthous ulcers: twin and pedigree data. Oral Surg Oral Med Oral Pathol 1977; 43: 886-91.

20. Pastore L, Carroccio A, Compilato D, Panzarella V, Serpico R, Lo Muzio L. Oral manifestations of celiac disease. J Clin Gastroenterol 2008; 42: 224-32.

21. Butbul Aviel Y, Tatour S, Gershoni Baruch R, Brik R. Colchicine as a therapeutic option in periodic fever, aphthous stomatitis, pharyngitis, cervical adenitis (PFAPA) syndrome. Semin Arthritis Rheum 2016; 45: 471-4.

22. Lin C-M, Wang C-C, Lai C-C, Fan H-C, Huang W-H, Cheng S-N. Genital ulcers as an unusual sign of periodic fever, aphthous stomatitis, pharyngotonsillitis, cervical adenopathy syndrome: a novel symptom? Pediatr Dermatol 2011; 28: 290-4.

23. Berk DR, Bayliss SJ. Neutrophilic dermatoses in children. Pediatr Dermatol 2008: 25: 509-19.

24. Dhopte A, Naidu G, Singh-Makkad R, Nagi R, Bagde H, Jain S. Psychometric analysis of stress, anxiety and depression in patients with recurrent aphthous Stomatitis-A cross-sectional survey based study. J Clin Exp Dent 2018; 10: e1109-e1114.

25. Neville B, Damm DD, Allen, CM, Bouquot JE. Oral and Maxillofacial Pathology. 3rd ed. St. Louis: Saunders; 2009.

26. Scully C, Porter S. Recurrent aphthous stomatitis: current concepts of etiology, pathogenesis and management. J Oral Pathol Med 1989; 18: 21-7.

27. Gürkan A, Özlü SG, Altıaylık-Özer P, Kurtul BE, Karacan CD, Senel S. Recurrent Aphthous Stomatitis in Childhood and Adolescence: A Single-Center Experience. Pediatr Dermatol 2015; 32: 476-80.

28. Brooke RI, Sapp JP. Herpetiform ulceration. Oral Surg Oral Med Oral Pathol 1976; 42: 182-8.

29. Shashy RG, Ridley MB. Aphthous ulcers: a difficult clinical entity. Am J Otolaryngol 2000; 21: 389-93.

30. Tarakji B, Gazal G, Al-Maweri SA, Azzeghaiby SN, Alaizari N. Guideline for the diagnosis and treatment of recurrent aphthous stomatitis for dental practitioners. J Int Oral Health 2015; 7: 74-80.

31. Poleník P. Recidivující aftózní stomatitida u dětí. Pediatr Praxi 2018; 19: 146-50.

32. Brocklehurst P, Tickle $M$, Glenny A-M, et al. Systemic interventions for recurrent aphthous stomatitis (mouth ulcers). Cochrane Database Syst Rev 2012; 9: CD005411.

33. Volkov I, Rudoy I, Freud T, et al. Effectiveness of vitamin B12 in treating recurrent aphthous stomatitis: a randomized, double-blind, placebo-controlled trial. J Am Board Fam Med 2009; 22: 9-16.

34. Chandrasekhar J, Liem AA, Cox NH, Paterson AW. Oxypentifylline in the management of recurrent aphthous oral ulcers: an open clinical trial. Oral Surg Oral Med Oral Pathol Oral Radiol Endod 1999; 87: 564-7.

35. Ivančaková R. Recidivující afty a jejich léčba v dětském věku. Pediatr Praxi 2014; 15: 57.

36. Wallace A, Rogers HJ, Hughes SC, et al. Managemet of recurrent aphthous stomatitis in children. Oral Medicine 2015; 42(6): 564-6, $569-72$. 